\title{
The multiple face(t)s of state conscientiousness: Predicting task performance and organizational...
}

Article in Journal of Research in Personality · June 2016

DOI: $10.1016 / j . j r p .2016 .06 .009$

CITATION

1

3 authors:

\section{Jonas Debusscher}

Vrije Universiteit Brussel

9 PUBLICATIONS 25 CITATIONS

SEE PROFILE

Filip De Fruyt

Ghent University

189 PUBLICATIONS $\quad 5,133$ CITATIONS

SEE PROFILE
READS

150

\section{Joeri Hofmans}

Vrije Universiteit Brussel

82 PUBLICATIONS 691 CITATIONS

SEE PROFILE

Some of the authors of this publication are also working on these related projects:

Project

Trajectories of attitudinal and behavioral reactions in the aftermath of psychological contract breach and violation View project 


\title{
The multiple face(t)s of state conscientiousness: Predicting task performance and organizational citizenship behavior ${ }^{\text {th }}$
}

\author{
Jonas Debusscher, ${ }^{\mathrm{a}, *}$ Joeri Hofmans, ${ }^{\mathrm{a}}$ Filip De Fruyt ${ }^{\mathrm{b}}$ \\ a Vrije Universiteit Brussel, Faculty of Psychology and Educational Sciences, Pleinlaan 2, 1050 Brussels, Belgium \\ ${ }^{\mathrm{b}}$ Ghent University, Department of Developmental, Personality and Social Psychology, H. Dunantlaan 2, 9000 Ghent, Belgium
}

\section{A R T I C L E I N F O}

\section{Article history:}

Received 14 September 2015

Received in revised form 21 March

2016

Accepted 4 June 2016

Available online $\mathrm{xxx}$

Keywords:

State conscientiousness

Facets

Performance

\begin{abstract}
A B S T R A C T
Previous studies have shown that conscientiousness facets incrementally predict performance above and beyond trai conscientiousness. In the present paper we investigate whether this finding also holds at the daily level. We conducted a ten-day experience sampling study assessing state conscientiousness in the morning and task performance and organizational citizenship behavior (OCB) in the afternoon. Using multilevel bi-factor modeling we show that general state conscientiousness positively predicts both task performance and OCB. Moreover, self-discipline and deliberation showed incremental predictive validity above and beyond overall state conscientiousness in the prediction of daily task performance, whereas none of the state conscientiousness facets uniquely predicted daily OCB levels.
\end{abstract}

(C) 2016 Published by Elsevier Ltd.

\section{Introduction}

Studies on the personality-performance relationship have consistently found that conscientiousness is among the best personality predictors of performance (Biderman, Nguyen, \& Sebren, 2008; Hurtz \& Donovan, 2000; LaHuis, Martin, \& Avis, 2005; Witt \& Ferris, 2003). At the same time, however, there is widespread agreement that the predictive validity of trait conscientiousness - and that of the Big Five traits in general-is rather limited. For example, a meta-analysis of Judge, Klinger, Simon, and Yang (2008) revealed that about $8 \%$ of the variance in employee job performance is explained by betweenperson differences in conscientiousness. To address this issue, several researchers examined moderators of the conscientiousness-performance relationship (e.g. Meyer, Dalal, \& Bonaccio, 2009), while others have tested whether the more narrow conscientiousness facets (i.e., the lower-order dimensions underlying trait conscientiousness) offer additional predictive validity on top of general trait conscientiousness (Hogan \& Holland, 2003; Tett, Steele, \& Beauregard, 2003).

Apart from the quest to maximize the predictive validity of personality, looking at the predictive role of facets is also interesting from a theoretical point of view. The reason is that, although broad factors tend to robustly relate to outcome variables, they typically obscure the predictive power of the underlying facets, thereby limiting a more sophisticated understanding of the role of personality in applied settings (McAbee, Oswald, \& Connelly, 2014). For example, al-

\footnotetext{
4 This work was supported by the Agency for innovation through science and technology (IWT) under Grant 121358 and by the Fonds Wetenschappelijk Onderzoek - Vlaanderen (FWO) under Grant G.0237.13N..

* Corresponding author.

Email addresses: jonas.debusscher@vub.ac.be (J. Debusscher); joeri.hofmans@ vub.ac.be (J. Hofmans); Filip.DeFruyt@UGent.be (F. De Fruyt)
}

though it makes sense for an organization to look for highly conscientious candidates, one might in fact search for someone high on achievement striving and low on conformity when recruiting for a start-up company, while someone low on achievement striving and high on conformity might be sought after when hiring for the function of security monitor (Oswald \& Hough, 2011). Such important nuances get lost when neglecting the facets as they are then mixed up in the general conscientiousness construct. Because of this reason, research involving facets has the potential to provide "a more substantive understanding of the relationships between personality and criterion variables of importance to organizations" (Oswald \& Hough, 2011, p. 157) and therefore such studies hold the promise of facets as components of improved theory, model building, and validity.

In a recent study on the unique predictive validity of conscientiousness facets for academic performance outcomes, McAbee et al. (2014) found that several of the conscientiousness facets predicted academic performance outcomes above and beyond general trait conscientiousness. In the present study we address a similar question, but in a work context. In particular, we study whether conscientiousness facets predict work performance above and beyond general conscientiousness. However, unlike McAbee et al. (2014), we do not focus on between-person differences, but on within-person, daily effects of conscientiousness on performance. This focus on the daily effects is important for at least two reasons. First, it is increasingly recognized that personality is a process that is embedded in day-to-day behavior (Brown \& Moskowitz, 1998). The implication of this embeddedness is that, while traits might be useful when the focus is on global functioning of the individual across time (i.e., describing how people are), they are less useful when it comes to providing pictures of day-to-day behavior expression. Because such day-to-day variation in the expression of behavior is a central feature of personality (Brown \& Moskowitz, 1998; Mischel \& Shoda, 1995), there is a need for research that studies what people actually do in their day-to-day lives 
(Fleeson \& Jayawickreme, 2015). Second, if our study can show that the relationship between conscientiousness and performance is not limited to a co-occurrence of differences between individuals, but really characterizes psychological functioning, it incorporates the conscientiousness-performance relationship in the realm of basic processes of psychological functioning (Fleeson, Malanos, \& Achille, 2002). In other words, it would show that it is really the act of being conscientious that is central to the conscientiousness-performance relationship.

In the remainder of this introduction we first give a short overview on the conscientiousness-performance relationship and discuss the importance of studying conscientiousness facets in addition to general conscientiousness. Next, we shift attention from the trait to the day-today level, and finally we discuss how daily conscientiousness (and its facets) is expected to relate to daily work performance.

\subsection{The conscientiousness-performance relationship}

Several meta-analyses have shown that, among the Big Five personality dimensions, conscientiousness is the best personality predictor of job performance (Barrick \& Mount, 1991; Hurtz \& Donovan, 2000; Salgado, 1997). The reason is that people high in conscientiousness are typically organized, exacting, disciplined, diligent, dependable, methodical, and purposeful (Witt, Burke, Barrick, \& Mount, 2002), all of which are believed to promote job performance.

General job performance, in turn, pertains to the degree to which an individual performs well in her/his job, but it can also be split into several sub-dimensions. In the present study we will make a broad distinction between in-role task performance and extra-role organizational citizenship behavior (OCB). Task performance is defined by Borman and Motowidlo (1993) as activities that are formally recognized as being part of the job and that contribute to the technical core of the organization. In contrast, OCB is defined as behavior that contributes to the goals of the organization by contributing to the organization's social and psychological environment (Rotundo \& Sackett, 2002). In previous meta-analyses the correlations of trait conscientiousness with task performance generally range between 0.20 and 0.31 (Barrick \& Mount, 1991; Hurtz \& Donovan, 2000; Salgado, 1997), while LePine, Erez, and Johnson (2002) report a correlation of 0.19 between conscientiousness and OCB.

\subsection{Conscientiousness: from the broad trait to narrow facets}

Whereas broad personality traits are useful when the goal is to obtain a rapid and general snapshot of someone's personality, facets (i.e., the lower-order dimensions underlying the broad trait) are typically favored when a more detailed assessment of personality is required (Costa \& McCrae, 1995). Moreover, because the facets contain information that is not necessarily reflected in the broad trait, facets might also enhance the predictive validity of personality (Tett et al., 2003). Finally, facets allow for a more sophisticated understanding of the role of personality in applied settings because they reveal which ingredients of the broad trait are relevant for the outcomes at hand (McAbee et al., 2014). Given the potential benefits of the use of facet scores, it is not surprising that different facet scales have been developed over the course of several years. However, the number and content of these facets has been the target of numerous debates. For example, DeYoung, Quilty, and Peterson (2007) developed two facet scales for each Big Five personality dimension. In turn, Roberts, Bogg, Walton, Chernyshenko, and Stark (2004)—using a lexical approach - represented the lower-order structure of conscientiousness using eight sub-components, while Roberts, Chernyshenko,
Stark, and Goldberg (2005)—based on a factor analysis of seven conscientiousness scales-found a hierarchical structure with six subcomponents. Finally, also Costa and McCrae (1992) proposed a sixfacet structure for each Big Five trait, although this six-facet structure differed from the one of Roberts et al. (2005).

In the present study we draw on the six-facet structure of Costa and McCrae (1992). According to this conceptualization, a first conscientiousness facet is competence, which encompasses the sense that one is capable, sensible, and accomplished. Order refers to the tendency to keep one's environment tidy and well-organized. Dutifulness in turn reflects a strict adherence to standards of conduct, whereas achievement striving involves a striving for excellence. Persistence or the ability to continue with a task despite boredom or other distractions is captured by the facet self-discipline. Finally, deliberation is best described by caution, planning, and thoughtfulness or put differently, the degree to which people think before they act.

\subsection{From trait to state conscientiousness}

Traditionally, it is assumed that people are relatively stable in their cognitions, affects and behaviors across time and situations (Goldberg, 1990). These stable personality dimensions have been conceptualized using different taxonomies, of which the Big Five taxonomy is the most well-known and widespread. Recently, however, within-person variability in these cognitions, affects, and behaviors started to receive more attention (Fleeson, 2001).

These two streams are better known as the structural or trait approach and the process or social-cognitive approach to personality (Fleeson, 2001). The structural approach emphasizes broad behavioral tendencies, which in the literature are often referred to as personality traits. The process approach pertains to intra-individual variability within these broad tendencies. These deviations from the average level are referred to as personality states or momentary enactments that have "the same affective, behavioral, and cognitive content as their corresponding traits" (Fleeson, 2012, p. 52). Although the structural and process approaches focus on different aspects of personality, they are not mutually exclusive. On the contrary, both approaches are needed to obtain a good understanding of personality.

An integration of both approaches is exactly what 'Whole Trait Theory' (Fleeson \& Jayawickreme, 2015) pursues by building on the strengths of both the trait and social-cognitive approach. According to this integrative theory of personality, traits consist of an explanatory and a descriptive part. The explanatory part pertains to social-cognitive mechanisms such as goals, encodings, self-regulatory plans, and expectancies, which are all believed to differ within individuals and therefore determine how traits operate, come about, and how they can account for intra-individual differences in behavior. The descriptive side of traits can be conceptualized as density distributions of states. People think, behave, and feel differently in different situations and these differential patterns of behavior, affect, and cognition can be summarized as a distribution of states. These distributions thus capture individual differences in the momentary enactment of a trait and therefore reflect individual differences in individuals' state levels (Fleeson \& Jayawickreme, 2015).

In the present study we focus on personality states because according to Whole Trait Theory (Fleeson \& Jayawickreme, 2015) and the density distribution approach to personality, personality states are the building blocks of personality. Therefore, a good understanding of the functioning of personality implies that we need to understand how states work. Applied to this particular study, studying state conscientiousness allows testing whether the relationship between trait conscientiousness and performance is really rooted in psychological 
functioning. In other words, if we can show that it is really the act of being conscientious that is central to the conscientiousness-performance relationship, our findings would include the conscientiousnessperformance relationship in the realm of basic processes of psychological functioning and take it beyond simple co-variation at the betweenperson level (Fleeson et al., 2002).

\subsection{State conscientiousness and its facets as predictors of momentary performance}

As mentioned above, there is plenty of research that relates between-person differences in conscientiousness to between-person differences in performance (Biderman et al., 2008; Carter et al., 2013; Meyer et al., 2009), and also research on the between-person relationship between facets of conscientiousness and performance is well established. Chamorro-Premuzic and Furnham (2002) for example looked at how facets of conscientiousness related to academic performance. They found that especially dutifulness, achievement striving, and self-discipline were positively related to exam results. Furthermore, in their meta-analysis, Dudley, Orvis, Lebiecki, and Cortina (2006) found that the facets of conscientiousness incrementally predicted performance above and beyond trait conscientiousness.

As opposed to these between-person studies, research on the within-person relationship between conscientiousness and performance is scarce. Debusscher, Hofmans, and De Fruyt (2015), in their study on the role of within-person variability in personality states, were one of the few who empirically studied the within-person conscientiousness - task performance relationship. In this study, they found that state conscientiousness related positively to momentary task performance. However, they used a composite state conscientiousness score, which did not allow for an investigation of this relationship at the facet level. Moreover, we are not aware of any other studies that have examined the predictive validity of conscientiousness facets at the within-person level. This is an important gap in the literature because, if we want to arrive at a more sophisticated understanding of the role of daily effects in conscientiousness, research on state conscientiousness facets is needed. In the present study, we do this by relating daily conscientiousness to daily job performance. In line with the study of Debusscher et al. (2015), we expect a positive relationship of state conscientiousness on both task performance and OCB. The unique effects of the state conscientiousness facets on both performance dimensions will be investigated in an exploratory fashion.

Not only the shift from the between- to the within-person level is a non-trivial issue, also the modeling of the overall state conscientiousness and its facets is challenging. The reason is that the model should reflect the theoretical perspective the researcher holds regarding the functioning of the scale (Markon, 2009; McAbee et al., 2014). As personality inventories are typically designed to measure narrow personality facets that underlie a broad factor (Markon, 2009), there are two viable options. The first option is to model the personality structure using a higher-order factor model. In such higher-order factor models, the items load on specific facet factors, and these facet factors in turn load on a general factor. This model thus assumes that variation in the general factor is driven by variation in the narrow facet factors, which in turn determine variation in the personality item scores (see Fig. 1). The result of this modeling approach is that, although the facets define the content of the general conscientiousness dimension, the general dimension is of primary interest when predicting outcomes (McAbee et al., 2014). A second option to simultaneously model facet factors and the general factor is bi-factor modeling. The bi-factor model differs from the higher-order model in the sense that all items load simultaneously on both the general factor (i.e., general state conscientiousness) and on one of the facet factors (i.e., one of the state conscientiousness facets). Moreover, the general factor and all facet factors are independent from each other (see Fig. 2 ). By using this modeling approach, the bi-factor model explicitly recognizes that the items of the personality inventory share variation

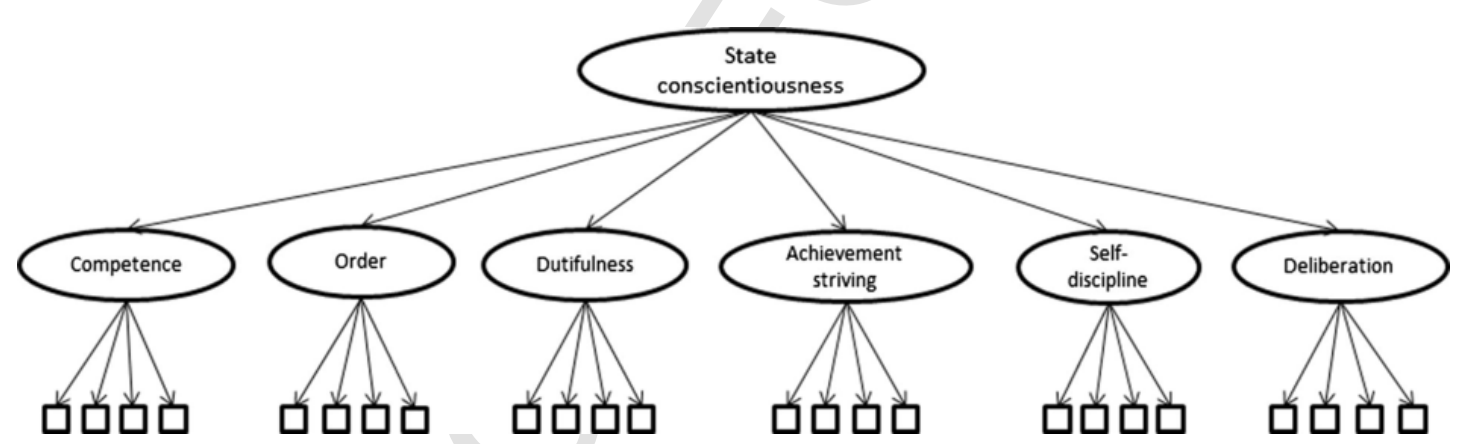

Fig. 1. Graphical representation of the second-order factor model for conscientiousness. The error variances associated with each item are not shown.

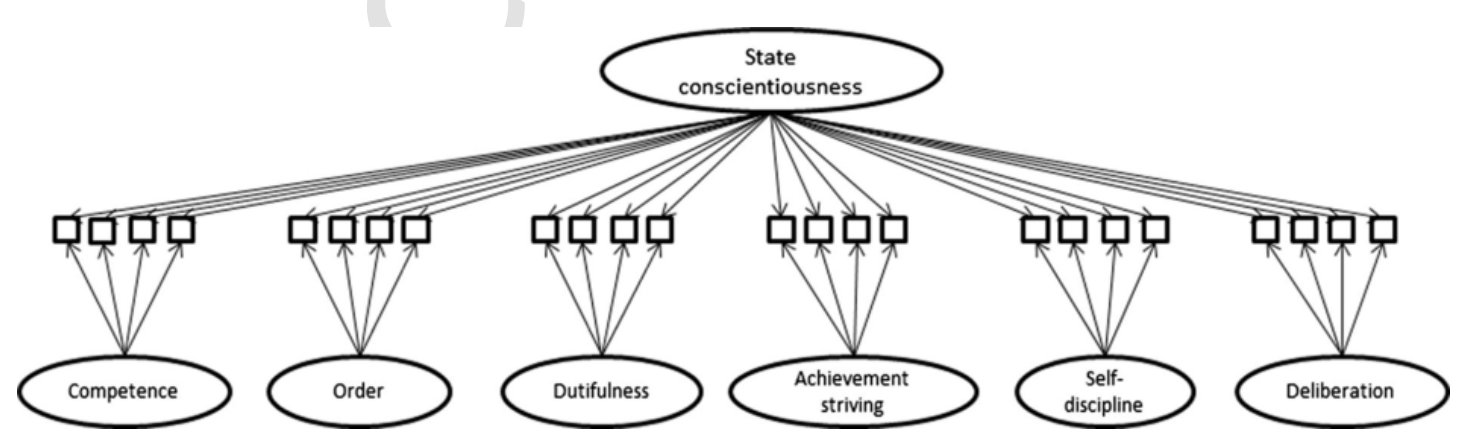

Fig. 2. Graphical representation of the bi-factor model for conscientiousness. The error variances associated with each item are not shown. 
with all other items because they all tap into the same general dimension, but also share variation with items measuring the same facet. Because these two types of variation are independent from each other, they can each be used to predict external outcomes, which makes the bi-factor model an interesting model from a theoretical point of view (McAbee et al., 2014).

\section{Method}

\subsection{Participants}

By means of a convenience sampling approach, 83 participants were contacted to partake in the study. Participants could not be selfemployed and they had to have access to a computer during their working days. These 83 employees were contacted via an online survey system, asking them to fill out a baseline questionnaire including several demographic variables. This baseline questionnaire was completed by 78 individuals of whom 50 were women. On average, respondents were 38.83 years old $(S D=13.27)$ and had an organizational tenure of 11.90 years $(S D=13.04)$. In terms of job content, the majority of participants worked in governmental and non-profit organizations (19.20\%), energy sector (16.70), healthcare (14.10), and professional services $(9.00 \%)$. Of these 78 participants, $79.50 \%$ had a full-time contract. Seventy-four of the employees who completed the baseline measure also took part in the experience sampling, which started one week after the baseline measure. Of these 74 employees, 64 had at least two full day observations (including conscientiousness and performance data) and could be used for further analyses. Note that a minimum of two full day observations is necessary as with only one observation for an individual it's impossible to separate the within- from the between-person variability.

\subsection{Procedure}

After having completed a baseline questionnaire in which demographic variables were assessed, participants enrolled in a ten-day experience sampling study. This experience sampling study consisted of two daily prompts that were sent to participants. During the morning prompt, which they received at a random point in time between 9:00 and 11:30 AM, state conscientiousness and its facets were assessed. The afternoon prompt was used to assess employees' task performance and OCB and was sent out each day at a random point in time between 14:40 and 16:30 PM. To avoid order effects all scales, as well as the items within each scale, were randomized. Only data from participants that filled out both the morning and afternoon prompt-with at least one hour in between their answers on both prompts-were retained for further analyses. Following this procedure 482 unique observations encompassing both a morning and evening prompt were collected out of a maximum of 640 ( 64 employees $\times 10$ days) data points. This corresponds to an overall response rate of $75.31 \%$. Of the 64 participants, nine had two full day observations, eight had three observations, three had four observations, eight had five observations, seven participants had six observations, seven had seven observations, eight had eight observations, seven had nine observations, and another seven participants had ten full day observations.

\subsection{Measures}

\subsubsection{State conscientiousness}

State conscientiousness was measured using the 48-item conscientiousness subscale of the NEO-PI-R of Costa and McCrae (1992).
The instructions of this scale were slightly adapted to allow for a daily measurement of conscientiousness by adding the prefix "Today..." to the items. These items had to be rated on a five-point scale, ranging from "completely disagree" to "completely agree". Since our data have a two-level structure and our focus lies on the within-person component of the variables we used the multilevel confirmatory factor analysis approach of Geldhof, Preacher, and Zyphur (2014) to test the reliability of this scale. This resulted in a within-person omega reliability coefficient for state conscientiousness of 0.91 .

\subsubsection{State conscientiousness facets}

State conscientiousness facets were calculated based on the 48 -item subscale of conscientiousness mentioned above. Each facet is calculated based on eight items of this 48 -item scale. The within-person omega reliability coefficients for the facets are 0.77 for competence, 0.49 for order, 0.46 for dutifulness, 0.75 for achievement striving, 0.79 for self-discipline, and 0.61 for deliberation.

\subsubsection{Task performance}

Task performance was measured using the seven-item task performance subscale of Williams and Anderson (1991). The items were also slightly adapted to allow for momentary self-ratings of task performance (e.g. "Today, I adequately completed assigned duties"). The seven items had to be rated on a seven-point scale, ranging from "completely disagree" to "completely agree". The within-person omega reliability coefficient equaled 0.72 .

\subsubsection{Organizational citizenship behavior}

OCB was measured using the eight-item scale developed by Dalal, Lam, Weiss, Welch, and Hulin (2009) which is specifically suited for daily measures of the construct (e.g. "Today, I went out of my way to include a co-worker in a conversation"). For each item the respondents had to indicate whether they had or had not performed the behavior during that specific working day. Given that OCB encompasses a set of behaviors that are conceptually related but not necessarily correlated (e.g., it is not because you helped a colleague that you also spoke highly about a coworker to others), no internal consistency reliability index was calculated (also see Dalal et al., 2009).

\section{Results}

\subsection{Measurement models for state conscientiousness}

The measurement model at the within-person level was tested through a series of multilevel exploratory (EFA) and multilevel confirmatory factor analyses (CFA) in Mplus version 7.31 (Muthén \& Muthén, 1998-2012). In a first step, one-factor multilevel EFAs were conducted for each individual facet with the goal of constructing item parcels. More specifically, following McAbee et al. (2014), we adopted a strategy in which we first combined the two largest withinperson factor loadings in one facet, next the third and fourth largest, and so on. We continued with this procedure until we obtained four parcels for each state conscientiousness facet.

In a second step, we tested three alternative confirmatory factor models: a one-factor model, a second-order factor model, and a bifactor model (see McAbee et al., 2014 for an identical strategy). In the one-factor model all parcels loaded on a single within-person factor. In the second-order model all parcels loaded on their respective facet factor, and each facet factor in turn loaded on a second-order general conscientiousness factor. Note that this model implies that the relationships between the parcels and general state conscientiousness 
are fully mediated by the facets (McAbee et al., 2014). Finally, we also tested a bi-factor model in which each of the parcels not only loaded on a general state conscientiousness factor, but also on a specific, facet factor. Moreover, both the specific facet factors and the general factor were orthogonal. The idea underlying the bi-factor model is that variation in the item scores (or item parcels) can be separated in unique variation due to a general conscientiousness factor and unique variation due to specific facet factors. In each of these models, we saturated the between-person model, which means that we allowed for all possible correlations at the between-person level. To assess model fit, we compared each of the models to a baseline model with no co-variances at the within-person level (i.e., the worst possible within-person model), and a fully saturated model at the between-person level (i.e., the best possible between-person model). Because the only difference between the baseline model and the other models is the within-person part, computing the fit indices relative to this baseline model ensures that they reflect fit and misfit in the within-person model only (Ryu, 2014). Model fit was assessed using the Comparative Fit Index (CFI), the Root Mean Square Error of Approximation (RMSEA), and the Standardized Root Mean Residual (SRMR). Additionally, we also report the sample-size adjusted Bayesian Information Criterion (BIC), because this allows for between-model comparison.

Fit indices for the one-factor $\left(\chi^{2}=993.15, d f=252, \mathrm{CFI}=0.78\right.$, RMSEA $=0.08, \quad$ SRMR $=0.06, \quad$ sample-size $\quad$ adjusted $\mathrm{BIC}=16438.81)$, second-order $\left(\chi^{2}=624.29, d f=246, \mathrm{CFI}=0.89\right.$, RMSEA $=0.06, \quad$ SRMR $=0.06, \quad$ sample-size $\quad$ adjusted $\mathrm{BIC}=16144.87), \quad$ and bi-factor model $\left(\chi^{2}=487.01, \quad d f=232\right.$, $\mathrm{CFI}=0.93, \quad \mathrm{RMSEA}=0.05, \quad \mathrm{SRMR}=0.05$, sample-size adjusted $\mathrm{BIC}=16126.59)$ revealed that the bi-factor model fitted the data best. ${ }^{1}$ Having established the best measurement model for our data, we saved the within-person factor scores (for general state conscientiousness and the specific state conscientiousness facets) and used them as predictors of momentary task performance and momentary OCB in a next analysis. Whereas the interpretation of the factor scores for general state conscientiousness is relatively straightforward, the facet factor scores should be interpreted as residuals relative to general state conscientiousness, implying that they tap into the relative importance of each facet at each time point (DeMars, 2013). Therefore, we predict to what extent increases/decreases in the relative importance of the facets relate to increases/decreases in task performance and OCB at the daily level.

\subsection{Predicting performance from the bi-factor factor scores}

Descriptive statistics, correlations, and intra-class correlations (ICCs) for all study variables are shown in Table 1 . As our data have a two-level structure (i.e., $i$ measurements nested within $j$ persons) we modeled our data using multilevel analyses. Task performance was modeled as a continuous outcome, whereas OCB was modeled as a count variable in the two-level path model. In this path model, momentary task performance and momentary OCB were predicted from the within-person factor scores on the five remaining state conscientiousness facets and from the within-person factor scores on the gen-

\footnotetext{
${ }^{1}$ When testing the bi-factor model, we encountered a convergence problem. This was due to the fact that none of the achievement striving parcels loaded significantly on their respective facet factor. Because of this reason, we removed the achievement striving facet factor from the model.
}

eral state conscientiousness factor. ${ }^{2}$ Before testing the final model we tested whether the relationships between the predictors and the outcomes were participant-specific. We did this by testing - for each slope separately - whether a model with a random slope fitted our data better than a model without such a random slope. If the slope variance turned out to be statistically significant it was included in the model, if not, the random slope was trimmed (see Sieracki, Leon, Miller, \& Lyons, 2008).

A summary of the path coefficients and their associated slope variance is shown in Table 2 . We see that for OCB only general state conscientiousness significantly predicted OCB $(\beta=0.15,95 \%$ CI [0.04, $0.25]$ ). None of the conscientiousness facets had additional predictive validity above and beyond general state conscientiousness (see Fig. 3).

The general state conscientiousness factor also significantly predicted task performance $(\beta=0.63,95 \% C I[0.40,0.87])$, but also selfdiscipline $(\beta=0.32,95 \% C I[0.09,0.54])$ and deliberation $(\beta=0.30$, $95 \%$ CI $[0.08,0.52])$ had unique, significant positive effects on task performance. The other three facets were unrelated to task performance (see Fig. 4).

\section{Discussion}

Our findings replicated the recent findings of Debusscher et al. (2015), who found a positive relationship between general state conscientiousness and performance. In particular, we demonstrated that, at the daily level, overall state conscientiousness related positively to OCB and task performance, suggesting that when someone behaves in a conscientious way, his or her job performance is positively impacted.

Regarding the unique predictive validity of the state conscientiousness facets, we found that none of them related uniquely to OCB, while self-discipline and deliberation were positively related to task performance. Although self-discipline and deliberation share an inhibitive element (see Costa, McCrae, \& Dye, 1991) their inhibitive nature cannot fully explain their unique relationships with task performance as there are two other inhibitive facets (i.e., order and dutifulness) that were unrelated to task performance. What differentiates them is that self-discipline and deliberation both tap into self-control, while order and dutifulness pertain more to adherence to structure and rules. As task performance pertains to the formally recognized part of the job, people are contractually commanded to perform these tasks, even on moments and in situations when their momentary level of motivation is low. On these less inspiring moments, self-control is adaptive to perform well. That is, continuing despite boredom or other distractions (i.e., self-discipline) and being cautious, planning ahead, and being thoughtful (i.e., deliberation) is required when the momentary level of motivation is low. In turn, self-control is less relevant when it comes to OCB, which by definition is proactive in nature (Carpenter, Berry, \& Houston, 2014). That is, because one typically engages in OCB on a voluntarily basis, self-discipline is less of an issue. Moreover, as OCB often entails a direct response to things that happen in one's environment (e.g. helping a colleague who is in need), deliberation is also less relevant. In sum, our findings suggest that the element of self-control is not fully captured by overall con-

\footnotetext{
${ }^{2}$ The achievement striving facet was not part of this analysis since the parcels had no significant loadings on the facet factor. This implies that there is no specific variance left when the variance that is shared with the other factors is accounted for, which means that the achievement striving facet is entirely absorbed in the overall state conscientiousness factor.
} 
Table 1

Means, standard deviations, intra-class correlations, and (within-person) correlations of all study variables.

\begin{tabular}{|c|c|c|c|c|c|c|c|c|c|c|c|c|c|}
\hline & $M$ & $S D$ & $\mathrm{ICC}_{\text {Person }}$ & ICC $_{\text {Measurement }}$ & 1. & 2. & 3. & 4. & 5. & 6. & 7. & 8. & 9. \\
\hline 1. General state $\mathrm{C}$ & 3.73 & 0.38 & 0.58 & 0.42 & 1.00 & - & - & - & - & - & - & - & - \\
\hline 2. Competence & 3.79 & 0.49 & 0.48 & 0.52 & $0.77^{* *}$ & 1.00 & - & - & - & - & - & - & - \\
\hline 3. Order & 3.55 & 0.50 & 0.63 & 0.37 & $0.67^{* *}$ & $0.39^{* * *}$ & 1.00 & - & - & - & - & & - \\
\hline 4. Dutifulness & 4.04 & 0.41 & 0.61 & 0.39 & $0.66^{* *}$ & $0.42 * *$ & $0.35^{* *}$ & 1.00 & - & - & - & - & - \\
\hline 5. Achievement striving & 3.53 & 0.54 & 0.51 & 0.49 & $0.80^{* *}$ & $0.53^{* *}$ & $0.42 * *$ & $0.47^{* *}$ & 1.00 & - & - & - & - \\
\hline 6. Self-discipline & 3.67 & 0.57 & 0.42 & 0.58 & $0.80^{* *}$ & $0.53^{* *}$ & $0.45^{* *}$ & $0.42^{* *}$ & $0.63^{* *}$ & 1.00 & - & - & - \\
\hline 7. Deliberation & 3.77 & 0.51 & 0.58 & 0.42 & $0.63^{* *}$ & $0.44 * *$ & $0.36^{* *}$ & $0.32 * *$ & $0.34^{* *}$ & $0.32^{* *}$ & 1.00 & - & - \\
\hline 8. OCB & 5.91 & 1.70 & 0.51 & 0.49 & $0.21^{* *}$ & $0.20^{* *}$ & 0.10 & $0.14^{* *}$ & $0.15^{* *}$ & $0.18^{* *}$ & $0.13^{* *}$ & 1.00 & - \\
\hline 9. Task performance & 5.31 & 0.74 & 0.56 & 0.44 & $0.40^{* *}$ & $0.26^{* *}$ & $0.24 * *$ & $0.22^{* *}$ & $0.33^{* *}$ & $0.37^{* * *}$ & $0.32 * *$ & $0.22^{* *}$ & 1.00 \\
\hline
\end{tabular}

Notes: $\mathrm{C}=$ conscientiousness; $\mathrm{OCB}=$ organizational citizenship behavior.

** $p<0.01$.

Table 2

Overview of the results of the two-level path analysis.

\begin{tabular}{lrll}
\hline & Slope & $95 \%$ CI & Slope variance \\
\hline General state $\mathrm{C} \rightarrow$ OCB & $\mathbf{0 . 1 5}$ & {$[\mathbf{0 . 0 4 - 0 . 2 5}]$} & - \\
Competence $\rightarrow$ OCB & 0.09 & {$[-0.14$ to 0.32$]$} & - \\
Order $\rightarrow$ OCB & -0.12 & {$[-0.37$ to 0.14$]$} & - \\
Dutifulness $\rightarrow$ OCB & 0.19 & {$[-0.17$ to 0.54$]$} & 0.001 \\
Self-discipline $\rightarrow$ OCB & 0.09 & {$[-0.06$ to 0.23$]$} & - \\
Deliberation $\rightarrow$ OCB & 0.09 & {$[-0.01$ to 0.19$]$} & - \\
General state C $\rightarrow$ task performance & $\mathbf{0 . 6 3}$ & {$[\mathbf{0 . 4 0}-\mathbf{0 . 8 7}]$} & 0.32 \\
Competence $\rightarrow$ task performance & 0.19 & {$[-0.27$ to 0.64$]$} & - \\
Order $\rightarrow$ task performance & 0.05 & {$[-0.52$ to 0.61$]$} & - \\
Dutifulness $\rightarrow$ task performance & -0.03 & {$[-0.89$ to 0.83$]$} & 1.88 \\
Self-discipline $\rightarrow$ task performance & $\mathbf{0 . 3 2}$ & {$[\mathbf{0 . 0 9}-\mathbf{0 . 5 4}]$} & - \\
Deliberation $\rightarrow$ task performance & $\mathbf{0 . 3 0}$ & {$[\mathbf{0 . 0 8}-\mathbf{0 . 5 2}]$} & 0.21 \\
\hline
\end{tabular}

Notes: $\mathrm{CI}=$ confidence interval; $\mathrm{C}=$ conscientiousness; significant effects are in bold

scientiousness, and that this element is important for task performance but not for OCB.

Although it was not the main purpose of our study, our data also speak to the bandwidth-fidelity dilemma. According to this dilemma, a match between the bandwidth of the predictor and the outcome results in better predictive validity. More specifically, Ones and Viswesveran (1996) argue that broadly defined outcomes are best predicted by general traits, whereas more narrowly defined outcomes are better predicted by narrow facets. In support of this idea we indeed see that task performance and $\mathrm{OCB}$-both being rather broad performance dimensions - are best predicted by general state conscientiousness. However, at the same time we also found important differences between both outcomes. Whereas for OCB none of the state conscientiousness facets had additional predictive value, for task performance two facets did. Thus even within the same bandwidth, facets might be relevant for one but not for another outcome. This illustrates that the choice for broad versus narrow predictors should not only be a matter of the bandwidth of the criterion, but also of the extent to which the predictors are thought to tap into the mechanisms underlying the predictor-criterion relationship.

\subsection{Limitations and future research}

In the present study, we focused on the unique predictive validity of conscientiousness facets, building on the idea that an understanding thereof allows for a more sophisticated understanding of the effect of conscientiousness on performance. To this end, we studied the sixfacet structure of Costa and McCrae (1992). Whereas this facet structure and the associated NEO-framework is widely known and often used, there are alternative facet structures that are based on a thorough vetting of the domain and might therefore provide even more specificity (see Roberts et al., 2004, 2005). For example, the eight facet structure of conscientiousness proposed by Roberts et al. (2004) includes two facets (i.e., formalness and conventionality) that are not included in other facet structures and therefore this facet structure might allow for even more sophisticated insights into the conscientiousnessperformance relationship.

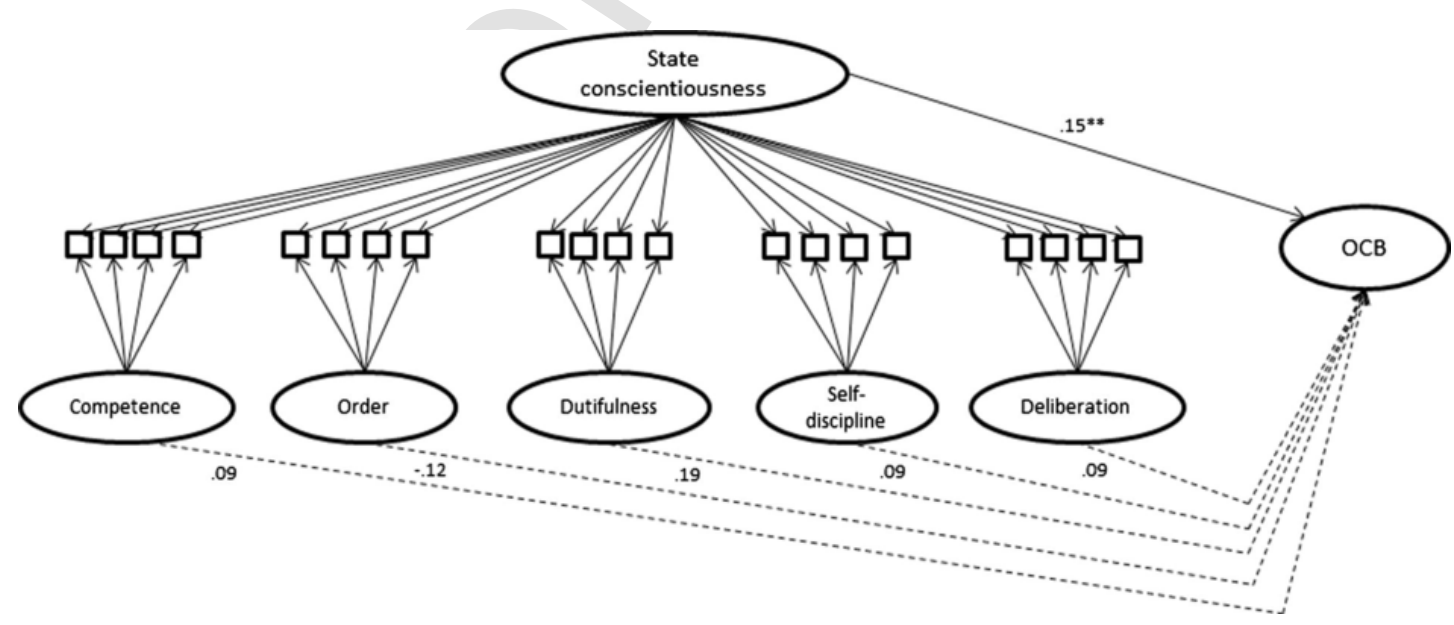

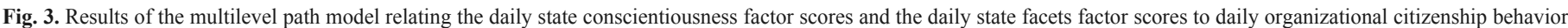
(OCB). All regression weights represent within-person associations. The error variances associated with each item are not shown. 


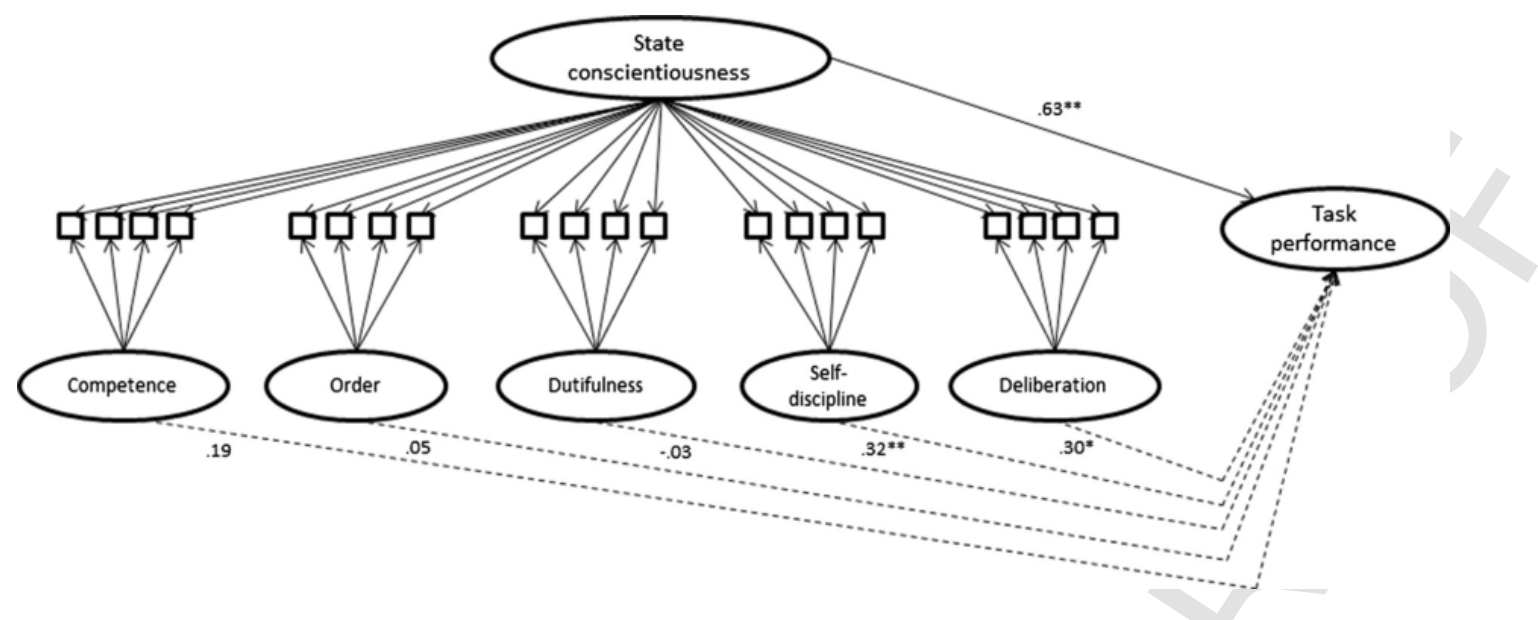

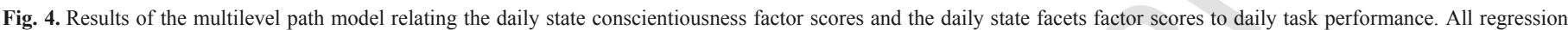
weights represent within-person associations. The error variances associated with each item are not shown.

A second limitation of our study is the use of a convenience sample. The primary downside of this technique is that our study sample may not be representative for the entire employee population. This limitation is however less of an issue in the current study as we focus purely on within-person relationships, which implies that we compare each employee to him-/herself, rather than to other employees.

A third limitation is that we used self-rated reports for both conscientiousness and performance. Although this increases the risk of the data being affected by common method bias, we tried to minimize such biases by including time lags in our study design (i.e., measuring state conscientiousness in the morning and both performance dimensions in the afternoon) (Podsakoff, MacKenzie, \& Podsakoff, 2012). An additional advantage of the use of these time lags is that they can show directionality of the effects.

An interesting avenue for future research would be to shift focus from the descriptive part of personality - which was investigated in this study - to the explanatory part. This would imply gaining further insights into the role of the social-cognitive mechanisms in the activation of broad personality states and narrow state facets (see Fleeson \& Jayawickreme, 2015 for a similar call). For state conscientiousness one could for example examine situational features that activate the different state conscientiousness facets. This is of particular importance since at different moments and in different situations, diverse conscientiousness facets may become more salient and therefore at various moments the momentary level of conscientiousness might be driven by different facets. For example, when an employee has to carry out a tedious administrative task, self-discipline and order may get activated, while if that same person needs to make a complex, high impact decision the deliberation facet might be more salient. As a result, in the first situation the momentary conscientiousness level is more colored by self-discipline, while in the second situation the momentary level of conscientiousness is driven more by deliberation. This is an important realization because, if facets have incremental validity over and above overall state conscientiousness, changes in the momentary constellation of conscientiousness may affect the strength of its relationship with job performance. Moreover, such a finding is also suggestive for the fact that "the general factor and specific facets operate through different mediating mechanisms" (McAbee et al., 2014, p. 615). Therefore, studying the predictive validity of within-person fluctuations in conscientiousness facets might contribute to a better understanding of the explanatory part of personality (Fleeson \& Jayawickreme, 2015) by shedding light on the mech- anisms underlying the conscientiousness-performance relationship in everyday life.

Based on previous empirical research we are confident that general state personality dimensions can be influenced by work related situational features. Debusscher, Hofmans, and De Fruyt (2016) for example showed that momentary levels of work pressure and task complexity are positively related to state neuroticism, while Minbashian, Wood, and Beckmann (2010) revealed that state conscientiousness is contingent on the difficulty and urgency of a task. For the facets of state conscientiousness, a similar reasoning can hold. When, for example, an employee is faced with a situation in which $\mathrm{s} /$ he has a lot of autonomy, the structural inhibitive facets of conscientiousness such as order and dutifulness can come to the forefront because they allow the individual to structure his/her work environment and to formulate personal deadlines. Another situational characteristic such as the complexity of the task that an employee needs to fulfill might activate the more proactive aspects of conscientiousness (Costa et al., 1991), such as the facets of competence and achievement striving, because these allow the employee to actively deal with the complex tasks and solve them successfully.

\section{Conclusion}

Our study showed that overall state conscientiousness positively predicts both daily OCB and task performance levels, whereas only two state conscientiousness facets (i.e., self-discipline and deliberation) had additional predictive validity over and above overall state conscientiousness in predicting daily levels of task performance. These results suggest that the element of self-control is not fully captured by overall conscientiousness, and that this element is important for task performance but not for OCB.

\section{References}

Barrick, M.R., Mount, M.K., 1991. The Big Five personality dimensions and job performance: A meta-analysis. Personnel Psychology 44, 1-26. http://dx.doi.org/10. 1111/j.1744-6570.1991.tb00688.x.

Biderman, M.D., Nguyen, N.T., Sebren, J., 2008. Time-on-task mediates the conscientiousness-performance relationship. Personality and Individual Differences 44, 887-897. http://dx.doi.org/10.1016/j.paid.2007.10.022.

Borman, W.C., Motowidlo, S.J., 1993. Expanding the criterion domain to include elements of contextual performance. In: Schmitt, N., Borman, W.C. (Eds.), Personnel selection in organizations. Jossey-Bass, San Francisco.

Brown, K.W., Moskowitz, D.S., 1998. Dynamic stability of behavior: The rhythms of our interpersonal lives. Journal of Personality 66, 105-134. http://dx.doi.org/10. 1111/1467-6494.00005. 
Carpenter, N.C., Berry, C.M., Houston, L., 2014. A meta-analytic comparison of selfreported and other-reported organizational citizenship behavior. Journal of Organizational Behavior 35, 547-574. http://dx.doi.org/10.1002/job.1909.

Carter, N.T., Dalal, D.K., Boyce, A.S., O’Connell, M.S., Kung, M., Delgado, K.M., 2013. Uncovering curvilinear relationships between conscientiousness and job performance: How theoretically appropriate measurement makes an empirical difference. Journal of Applied Psychology 99, 564-586. http://dx.doi.org/10.1037/ a0034688.

Chamorro-Premuzic, T., Furnham, A., 2002. Personality traits and academic examination performance. European Journal of Personality 17, 237-250. http://dx.doi.org/ 10.1002/per.473.

Costa, P.T., McCrae, R.R., 1992. Discriminant validity of NEO-PIR facets scales. Educational and Psychological Measurement 52, 229-237. http://dx.doi.org/10.1177/ 001316449205200128 .

Costa, P.T., McCrae, R.R., 1995. Domains and facets: Hierarchical personality assessment using the revised NEO personality inventory. Journal of Personality Assessment 64, 21-50. http://dx.doi.org/10.1207/s15327752jpa6401_2.

Costa, P.T., McCrae, R.R., Dye, D.A., 1991. Facet scales for agreeableness and conscientiousness: A revision of the NEO personality inventory. Personality and Individual Differences 12, 887-898. http://dx.doi.org/10.1016/0191-8869(91)90177-D.

Dalal, R.S., Lam, H., Weiss, H.M., Welch, E.R., Hulin, C.L., 2009. A within-person approach to work behavior and performance: Concurrent and lagged citizenshipcounterproductivity associations, and dynamic relationships with affect and overal job performance. Academy of Management Journal 52, 1051-1066. http://dx.doi. org/10.5465/AMJ.2009.44636148

Debusscher, J., Hofmans, J., De Fruyt, F., 2015. Do personality states predict momentary task performance? The moderating role of personality variability. Journal of Occupational and Organizational Psychology http://dx.doi.org/10.1111/joop. 12126.

Debusscher, J., Hofmans, J., De Fruyt, F., 2016. From state neuroticism to momentary task performance: A person $\times$ situation approach. European Journal of Work and Organizational Psychology 25, 89-104. http://dx.doi.org/10.1080/1359432X.2014. 983085.

DeMars, C.E., 2013. A tutorial on interpreting bifactor model scores. International Journal of Testing 13, 354-378. http://dx.doi.org/10.1080/15305058.2013.799067.

DeYoung, C.G., Quilty, L.C., Peterson, J.B., 2007. Between facets and domains: 10 aspects of the Big Five. Journal of Personality and Social Psychology 93, 880-896. http://dx.doi.org/10.1037/0022-3514.93.5.880.

Dudley, N.M., Orvis, K.A., Lebiecki, J.E., Cortina, J.M., 2006. A meta-analytic investigation of conscientiousness in the prediction of job performance: Examining the intercorrelations and the incremental validity of narrow traits. Journal of Applied Psychology 91, 40-57. http://dx.doi.org/10.1037/0021-9010.91.1.40.

Fleeson, W., 2001. Toward a structure- and process-integrated view of personality: Traits as density distributions of states. Journal of Personality and Social Psychology 80, 1011-1027. http://dx.doi.org/10.1037/0022-3514.80.6.1011.

Fleeson, W., 2012. Perspectives on the person: Rapid growth and opportunities for integration. In: Deaux, K., Snyder, M. (Eds.), The Oxford handbook of personality and social psychology. Oxford University Press, New York, NY, pp. 33-63.

Fleeson, W., Jayawickreme, E., 2015. Whole trait theory. Journal of Research in Personality 56, 82-92. http://dx.doi.org/10.1016/j.jrp.2014.10.009.

Fleeson, W., Malanos, A.B., Achille, N.M., 2002. An intra-individual process approach to the relationship between extraversion and positive affect: Is acting extraverted as "good" as being extraverted?. Journal of Personality and Social Psychology 83, 1409-1422. http://dx.doi.org/10.1037/0022-3514.83.6.1409.

Geldhof, G.J., Preacher, K.J., Zyphur, M.J., 2014. Reliability estimation in a multilevel confirmatory factor analysis framework. Psychological Methods 19, 72-91. http:// dx.doi.org/10.1037/a0032138.

Goldberg, L.R., 1990. An alternative "description of personality": The Big Five factor structure. Journal of Personality and Social Psychology 59, 1216-1229. http://dx. doi.org/10.1037/0022-3514.59.6.1216.

Hogan, J., Holland, B., 2003. Using theory to evaluate personality and job performance relations: A socioanalytic perspective. Journal of Applied Psychology 88, 100-112. http://dx.doi.org/10.1037/0021-9010.88.1.100.

Hurtz, G.M., Donovan, J.J., 2000. Personality and job performance. The Big Five revisited. Journal of Applied Psychology 85, 869-879. http://dx.doi.org/10.1037/ 0021-9010.85.6.869.

Judge, T.A., Klinger, R., Simon, L.S., Yang, I.W.F., 2008. The contributions of personality to organizational behavior and psychology: Findings, criticisms, and future research directions. Social and Personality Psychology Compass 2, 1982-2000. http://dx.doi.org/10.1111/j.1751-9004.2008.00136.x.

LaHuis, D.M., Martin, N.R., Avis, J.M., 2005. Investigating non-linear conscientiousness-job performance relations for clerical employees. Human Performance 18, 199-212. http://dx.doi.org/10.1207/s15327043hup1803 1.
LePine, J.A., Erez, A., Johnson, D.E., 2002. The nature and dimensionality of organizational citizenship behavior: A critical review and meta-analysis. Journal of Applied Psychology 87, 52-65. http://dx.doi.org/10.1037//0021-9010.87.1.52.

Markon, K.E., 2009. Hierarchies in the structure of personality traits. Social and Personality Psychology Compass 3, 812-826. http://dx.doi.org/10.1111/j.1751-9004. 2009.00213.x.

McAbee, S.T., Oswald, F.L., Connelly, B.S., 2014. Bifactor models of personality and college student performance: A broad versus narrow view. European Journal of Personality 28, 604-619. http://dx.doi.org/10.1002/per.1975.

Meyer, R.D., Dalal, R.S., Bonaccio, S., 2009. A meta-analytic investigation into the moderating effects of situational strength on the conscientiousness-performance relationship. Journal of Organizational Behavior 30, 1077-1102. http://dx.doi.org/ 10.1002/job.602.

Minbashian, A., Wood, R.E., Beckmann, N., 2010. Task-contingent conscientiousness as a unit of personality at work. Journal of Applied Psychology 95, 793-806. http:/ /dx.doi.org/10.1037/a0020016.

Mischel, W., Shoda, Y., 1995. A cognitive-affective system theory of personality: Reconceptualizing situations, dispositions, dynamics, and invariance in personality structure. Psychological Review 102, 246-268. http://dx.doi.org/10.1037/ 0033-295X.102.2.246.

Muthén, L.K., Muthén, B.O., 1998-2012. Mplus user's guide. Muthén \& Muthén, Los Angeles, CA.

Ones, D.S., Viswesveran, C., 1996. Bandwidth-fidelity dilemma in personality measurement for personnel selection. Journal of Organizational Behavior 17, 609-626. http://dx.doi.org/10.1002/(SICI)1099-1379(199611)17:6<609:: AID-JOB1828>3.0.CO;2-K.

Oswald, F.L., Hough, L.M., 2011. Personality and its assessment in organizations: Theoretical and empirical developments. In: Zedeck, S. (Ed.), APA handbook of industrial and organizational psychology. Selecting and developing members for the organization. APA handbooks in psychology, Vol. 2. American Psychological Association, Washington, DC, pp. 153-184.

Podsakoff, P.M., MacKenzie, S.B., Podsakoff, N.P., 2012. Sources of method bias in social science research and recommendations on how to control it. Annual Review of Psychology 63, 539-569. http://dx.doi.org/10.1146/annurevpsych-120710-100452.

Roberts, B.W., Bogg, T., Walton, K.E., Chernyshenko, O.S., Stark, S.E., 2004. A lexical investigation of the lower-order structure of conscientiousness. Journal of Research in Personality 38, 164-178. http://dx.doi.org/10.1016/ S0092-6566(03)00065-5.

Roberts, B.W., Chernyshenko, O.S., Stark, S.E., Goldberg, L.R., 2005. The structure of conscientiousness: An empirical investigation based on seven major personality questionnaires. Personnel Psychology 58, 103-139. http://dx.doi.org/10.1111/j. 1744-6570.2005.00301.x

Rotundo, M., Sackett, P.R., 2002. The relative importance of task, citizenship, and counterproductive performance to global ratings of job performance: A policy-capturing approach. Journal of Applied Psychology 87, 66-80. http://dx.doi.org/10. 1037/0021-9010.87.1.66.

Ryu, E., 2014. Model fit evaluation in multilevel structural equation models. Frontiers in Psychology http://dx.doi.org/10.3389/fpsyg.2014.00081.

Salgado, J.F., 1997. The five factor model of personality and job performance in the European Community. Journal of Applied Psychology 82, 30-43. http://dx.doi.org/ 10.1037/0021-9010.82.1.30.

Sieracki, J.H., Leon, S.C., Miller, S.A., Lyons, J.S., 2008. Individual and provider effects on mental health outcomes in child welfare: A three level growth curve approach. Children and Youth Services Review 30, 800-808. http://dx.doi.org/10. 1016/j.childyouth.2007.12.008.

Tett, R.P., Steele, J.R., Beauregard, R.S., 2003. Broad and narrow measures on both sides of the personality-job performance relationship. Journal of Organizational Behavior 24, 335-356. http://dx.doi.org/10.1002/job.191.

Williams, L.J., Anderson, S.E., 1991. Job satisfaction and organizational commitment as predictors of organizational citizenship and in-role behaviors. Journal of Management 17, 601-617. http://dx.doi.org/10.1177/014920639101700305.

Witt, L.A., Burke, L.A., Barrick, M.R., Mount, M.K., 2002. The interactive effects of conscientiousness and agreeableness on job performance. Journal of Applied Psychology 87, 164-169. http://dx.doi.org/10.1037/0021-9010.87.1.164.

Witt, L.A., Ferris, G.R., 2003. Social skill as moderator of the conscientiousness-performance relationship: Convergent results across four studies. Journal of Applied Psychology 88, 809-820. http://dx.doi.org/10.1037/0021-9010.88.5.809. 